\title{
Commercialisation of genetically modified crops in New Zealand
}

\author{
M.J. WILLOCKS \\ Monsanto NZ Ltd, Private Bag 13 905, Wellington
}

\begin{abstract}
Commercialisation of genetically modified organisms creates new challenges for marketers and developers of this technology. The cost of development is high, and the need to gain a return on investment that reflects this cost is critical to ensure that this technology is brought to New Zealand agriculture. A further challenge is that the regulatory requirements differ from those required for non-transgenic crops. Once introduced into the market, it is important to develop a product stewardship programme to ensure continued trait performance and prevent factors arising that will negate the value of these traits such as pest resistance.
\end{abstract}

Keywords: genetically modified organisms, market analysis, product stewardship, regulatory process, return on investment

\section{Introduction}

The ability to modify organisms to introduce traits of value through the insertion of specific genes is a technology that will bring enormous benefit to food producers and consumers. Commercialisation of this technology is recent with the first commercial commodity crop, Roundup Ready soy beans, being introduced to the US market in 1996. Acceptance of the technology by producers has been high with approximately $40 \%$ of the total soy area in the US being modified to tolerate Roundup herbicide, 3 years after market introduction. To ensure this new technology does not pose an adverse effect to health, safety and the environment a regulatory process has been set up to manage the introduction of new organisms. As this technology is seed delivered, new challenges are created in the way a return can be gained on the investment to develop the new organisms.

This paper discusses the process of commercialising new organisms in the New Zealand market. For simplicity, the focus will be on new plant varieties. At the time of writing, no organisms had been approved for commercial release in New Zealand. The paper is based therefore on limited experience in the New Zealand market.

\section{Key elements in the commercialisation process}

The commercial introduction of any new product requires a process that is well known, usually well executed, and should not be the topic of this paper.

This paper will address what the author believes to be the key differentiators or issues that make the commercial introduction of genetically modified organisms unique. They are: market analysis, development process, regulatory process, capturing a fair return for the investment, and product stewardship.

\section{Market analysis}

This is an important process in the introduction in any new product and is especially important when developing genetically modified organisms. The costs of developing a new crop variety are significant and the need to fully understand the market, the realistic potential, the barriers to entry, the cost of development and the added value that the proposed crop will offer the market are important. Market analysis should be the first step in a development programme and not the step that is taken just before entry into the market. Failure to complete an adequate market analysis may compromise the investment in research and development.

\section{Development process}

The development process can begin at a number of places in the overall procedure of developing a new crop.

It can start with the identification and isolation of a specific gene, licensing of a gene and inserting it into the desired plant, sourcing a parent of the crop that has already had the desired gene inserted, through to sourcing the variety from another breeding programme.

The most expensive and time consuming steps in the process are gene discovery and transformation. To conduct these steps requires a commitment to the full costs of developing a new crop. International regulatory requirements are such that a new transformation event, i.e., the insertion of a new gene, is the start of a new regulatory process. It is not acceptable to insert the gene and claim equivalence on the basis that the gene has already been inserted into the same species. Where 
the gene is inserted in the genome can have a significant effect on the performance of the plant, hence the requirement for the testing and regulatory process to be specific to the transformation event.

Where possible, the most efficient method of developing a new variety suitable for New Zealand conditions is to source a modified plant that could be used in a breeding programme. This plant would be put through the regulatory process and then be permitted to be used in breeding programmes, the subsequent progeny not having to go through the regulatory process. An example of this would be the development of Roundup Ready forage brassicas for New Zealand farmers. The cost of inserting the gene, ensuring stability of the construct, conducting a breeding and selection programme, and developing a regulatory support package is estimated (best guess) at around $\$ 10 \mathrm{M}$. The size of the New Zealand market would not warrant such an investment.

However to source Brassica rapa or B. napus which has had the Roundup Ready gene inserted and has the accompanying regulatory studies completed and using that in a local breeding programme is a more economical option and one that could be viable for the New Zealand market.

It is important that when embarking on a development process, the impact of regulatory costs is understood and factored into the decision making process.

\section{Regulatory process}

In New Zealand there are two regulatory processes. When introducing an organism that is capable of reproducing, an approval must be gained from ERMA (Environmental Risk Management Authority). If it is a foodstuff then it must have the approval of ANZFA (Australia New Zealand Food Authority). If it is both a living organism and a foodstuff, for example potato or edible fruit with viable seed, then it must gain approvals from both authorities before market introduction. The ERMA process is a process based on scientific evaluation and consultation with the relevant parties. The decision on whether to approve an application or not is based on an assessment of the benefits outweighing the risks that may result from such a release.

The information required to support an application includes:

- details of the parent organism such as identification, origin, parentage, survivability, dissemination, and geographical distribution.

- details of the genetic modification such as information on the construct, methods used for the modification, development method, description of introduced traits, stability of integration into the genome, expression and stability of the insert.

- information concerning the genetically modified plant. How the plant differs from the parent in survivability, dissemination, modes or rates of reproduction, agricultural performance and harvested product.

- assessments of effects on the environment, ecosystems and health. Are there any Maori culture and taonga issues.

- risk benefit analysis.

The data requirements are extensive and expensive to produce. If the starting point is an already transformed plant that has been approved by another regulatory authority then much of the information will have been produced. Local data required will relate to local environmental studies, risk benefit analysis and consultation with Maori and other interested groups.

Conducting a risk benefit analysis can potentially be an endless process. As science-based people we can look at the science, predict an outcome, assess the potential risk, and develop a solution to minimise the risk. However the potential risks are also in fields outside our normal expertise and these risks are often highlighted once the process becomes a public process. For instance, Monsanto is developing an application to introduce Roundup Ready canola into New Zealand. In the process we completed an evaluation of the possible effects of introducing the crop, including outcrossing, potential weediness and the risk benefit analysis. Subsequently a number of groups have raised issues that may or may not be relevant but will need to be addressed in the application through the public consultation process. Allowances have to be made for the associated costs of handling these potential concerns.

\section{Gaining a return on research and development investment}

This is a critical issue in the commercialisation of a genetically modified organism. The cost of development is high but as the improvement is seed delivered, there is the potential for the beneficiary to continue to gain the benefit through saving their own seeds. This is a disincentive for further development as the developer will not gain a fair return on their investment.

The traditional method for gaining a return for a new crop variety is through a royalty system but this is not always sufficient to cover the investment. Recovering the cost of development of a GMO may require a royalty structure that is greater than the cost of the seed.

One method used for cost recovery is for the farmer to enter a licensing agreement to use the modified seed in return for a fee and agreeing not to save seed for 
subsequent crop establishment. The licence fee is based on sharing the value that the modification brings the end user allowing the developer to more quickly recover their investment. For instance, the value of a gene which protects the plant against insect attack may be the saving in cost of insecticide applications, as well as yield and quality improvements. Another method of capturing the value could be through closed loop supply systems where the crop is grown on contract, with the developer of the improvement sharing in the value of the contract.

\section{Product stewardship}

This is the after sales service which is essential to ensure that the trait is performing to expectations, and that the long-term viability of the trait is not compromised through agricultural practices. Insect protection is a valuable trait, but it also comes with the risk of the target insects developing resistance to the trait. This resistance is overcome through a resistance minimisation strategy that the growers agrees to adhere to as part of the licensing agreement. An important component of the product stewardship process is to ensure that the strategy is followed.

\section{Summary}

Genetically modified organisms present new challenges to the marketer introducing these products into the market place. Cost of development is high, regulatory requirements are different from those for introducing new crop varieties, and the methods for ensuring there is a return on investment require new approaches to markets.

When initiating a research and development programme, it is important that consideration is given to these factors and a full market opportunity analysis is completed before committing funds to the project. As with many new technologies, it will be the large international agricultural markets that will drive the development of this technology and New Zealand agriculture will benefit through adapting the opportunities for use in New Zealand crops and pastures. 
